Cite this: RSC Advances, 2013, 3, 14281

\title{
A tetrameric hetero-octanuclear cyclic helicate formed from a bridging ligand with two inequivalent binding sites $\dagger$
}

Received 28th May 2013,

Accepted 5th July 2013

DOI: $10.1039 / c 3 r a 42598 c$

A. J. Metherell and M. D. Ward*

www.rsc.org/advances

\begin{abstract}
A bis-bidentate bridging ligand $\mathrm{H}_{2} \mathrm{~L}$ with inequivalent hard and soft binding sites (catecholate and pyrazolyl-pyridine, respectively) reacts with a mixture of $\mathrm{Ti}(\mathrm{IV})$ and $\mathrm{Zn}$ (II) ions to afford an octanuclear heterometallic $\mathrm{Ti}_{4} \mathrm{Zn}_{4}$ cyclic helicate formed from four dinuclear $\left\{\operatorname{TiZn}(\mu-\mathrm{L})_{2}\right\}$ units connected in a ring via methoxide ions.
\end{abstract}

Self-assembly is a regularly exploited method in coordination chemistry to combine large numbers of components in one edifice. ${ }^{1}$ This is illustrated particularly well in the formation of coordination cages or capsules from labile metal ions and simple bridging ligands, with (for example) Fujita's 'nanosphere' forming from 72 component parts, i.e. 24 metal ions and 48 ditopic bridging ligands. ${ }^{2}$ An example from our own group is a series of $\mathrm{M}_{16} \mathrm{~L}_{24}$ cages which contain forty components in a single assembly, ${ }^{3}$ and many other groups have reported self-assembled molecular species of comparable complexity. ${ }^{4}$

An important characteristic of most such assemblies is that, despite their structural complexity and the large number of component parts that assemble, they often contain only two types of component with all metal ions being the same and all ligands being the same. This inevitably limits the functional behaviour that can be built into the assemblies. We can imagine that a greater range of functional behaviour could be achieved if the component parts themselves have some useful function such as redox activity or magnetism for metal ions, or conformational switchability or luminescent excited states for ligands. Accordingly it is of value to investigate self-assembled systems containing three or more types of component part, as a way of increasing the possibilities for functional behaviour in self-assembled complexes. $^{1 a}$

There are many ways in which self-assembly of $>2$ different types of component can be achieved using orthogonal interactions to avoid unwanted combinations of subcomponents. ${ }^{1 a}$ In terms of

Department of Chemistry, University of Sheffield, Sheffield S3 7HF, UK.

E-mail: m.d.ward@sheffield.ac.uk

$\dagger$ Electronic supplementary information (ESI) available. CCDC reference numbers 941142 and 941143. For ESI and crystallographic data in CIF or other electronic format see DOI: 10.1039/c3ra42598c. For further information on crystal data, see footnote $\dot{t}$ simple metal/ligand combinations, this could mean one type of metal ion that selects for a mixture of two types of ligand during the assembly process, for either geometric or electronic reasons. This principle is illustrated by Lehn's Cu(I)-based cylindrical assemblies $^{5}$ and related trigonal-prismatic structures from Severin $^{6}$ and Mukherjee ${ }^{7}$ in which each metal ion connects to two different types of ligand. Alternatively, it could mean one ligand that selects for a mixture of different metal ions. This can be achieved if the ligand has two different binding sites which attract different types of metal ion, and this is well known in (for example) heteronuclear double or triple helicates based on bridging ligands with two different binding pockets. ${ }^{8}$

Additional examples have come from the groups of Shionoya, ${ }^{9}$ Wang, ${ }^{10}$ and Raymond. ${ }^{11}$ Shionoya and co-workers used a ligand with a pyridyl group as one terminus and a catecholate (cat ${ }^{2-}$ ) as the other; the pyridyl coordinates to $\mathrm{Pd}(\mathrm{II})$, and the catecholate to Ti(Iv), to give heterometallic cages or rings depending on stoichiometry and reaction conditions. ${ }^{9}$ Wang and co-workers used a pyridyl/acetylacetonate ligand to prepare an $\mathrm{Al}(\mathrm{acac})_{3}$ unit with pendant pyridyl groups which combined with $\mathrm{Pd}$ (II) ions to form a heterometallic cubic cage. Raymond and co-workers used a simple ligand with phosphine and catechol binding sites which combines with a mixture of Ti(IV) and $\mathrm{Pd}(\mathrm{II})$ ions; the resulting $\mathrm{Ti}_{2} \mathrm{Pd}_{3} \mathrm{~L}_{6}$ assembly forms not only because of the preferences of the 'hard' and 'soft' metal cations for the catecholate and phosphine binding sites respectively, but also exploits the stereochemical preferences of the metal ions - octahedral for Ti(IV) and square planar for Pd(II). ${ }^{11}$

It is this last strategy that we exploit in this work. We have used ligands containing bidentate pyrazolyl-pyridine (pypz) termini as the basis of an extended family of self-assembled coordination cages using relatively soft $\mathrm{M}^{2+}$ cations which form $\left[\mathrm{M}(\mathrm{pypz})_{3}\right]^{2+}$ vertices. $^{3,12}$ In contrast, Raymond ${ }^{13}$ and Albrecht ${ }^{14}$ have used ligands containing catecholate termini that combine with harder metal cations to form anionic cages based on $\left[\mathrm{M}(\mathrm{cat})_{3}\right]^{n-}$ vertices. We report here the preparation of a new bridging ligand which combines 'hard' catecholate and 'soft' pyrazolyl-pyridine termini connected to an aromatic spacer. This opens up new possibilities to prepare heterometallic assemblies based on two types of metal 
<smiles>C=C=CCc1cccc(NC(=O)c2cccc(O)c2O)c1</smiles>

Scheme 1 The new ligand $H_{2} L$ and the main disconnections involved in its synthesis.

ion with differing affinities for the two types of terminus, and as a first example we present the example of an unusual heterometallic cyclic helicate which is a cyclic tetramer of dinuclear double helicate subunits.

The new ligand $\mathrm{H}_{2} \mathrm{~L}$ is shown in Scheme 1 along with a disconnection into component parts which forms the basis of the synthetic strategy. The catechol terminus is connected to the aromatic spacer via an amide linkage formed between an aromatic amine and an acyl chloride; the pyrazolyl-pyridine unit is connected via reaction of the deprotonated pyrazole unit with a $-\mathrm{CH}_{2} \mathrm{Br}$ group on the central spacer. The full synthesis is shown in Scheme 2 and starts from 3-amino-benzyl alcohol. Boc protection of the amine group allows the alcohol to be converted to a $-\mathrm{CH}_{2} \mathrm{Br}$ group, to which the pyrazolyl-pyridine unit is connected to give $\mathbf{3}$. Removal of the Boc group liberates the amine which condenses with the acyl chloride group of $\mathbf{5}$ to attach the dimethoxybenzene group to the central spacer (6); the final step is removal of the methyl groups with $\mathrm{BBr}_{3}$ to liberate the catechol of $\mathrm{H}_{2} \mathrm{~L}$. All new compounds were fully characterised by standard methods (see ESI $\dagger$ ).

The ${ }^{1} \mathrm{H}$ NMR spectrum of $\mathrm{H}_{2} \mathrm{~L}$ in $\mathrm{d}^{6}$-DMSO confirmed its structure; an expansion of the aromatic region (with assignments) is in ESI. $\nmid$ The ES mass spectrum showed a molecular ion at $\mathrm{m} / \mathrm{z}$ $387(\mathrm{M}+\mathrm{H})^{+}$. Crystals of $\mathrm{H}_{2} \mathrm{~L}$ (as its hydrobromide salt) were grown by diffusion of diethyl ether vapour into a solution in $\mathrm{MeOH} / \mathrm{CHCl}_{3}$ and the crystal structure is shown in Fig. 1. There is one complete ligand (and one $\mathrm{HBr}$ ) in the asymmetric unit. The catechol oxygen atoms are arranged syn to the amide carbonyl, as this allows the formation of a 6-membered hydrogen-bonded ring with a catechol $\mathrm{O}-\mathrm{H}$ bonded to the carbonyl oxygen $\mathrm{O}(43)$. Raymond and co-workers have reported this effect with their catecholamide ligands. ${ }^{15}$ The crystal structure also reveals that the bromide anion forms a variety of close contacts with protonated ligand molecules (numerous $\mathrm{H} \cdots \mathrm{Br}$ contacts of $c a$. 2.9-3 involving $\mathrm{CH}$ and $\mathrm{NH}$ bonds), with one interaction being notably shorter than the others: this is an $\mathrm{N}^{+}-\mathrm{H} \cdots \mathrm{Br}^{-}$hydrogen bond involving a protonated pyridine ring $[\mathrm{N}(11) \cdots \mathrm{Br}(1), 3.21 \AA$; $\mathrm{H}(11) \cdots \mathrm{Br}(1), 2.41 \AA$ ㄱ].

We combined $\mathrm{H}_{2} \mathrm{~L}$ with a mixture of $\mathrm{Zn}$ (II) and $\mathrm{Ti}(\mathrm{IV})$ salts, which are expected to interact with the pypz and catecholate termini respectively. There could be many ways in which the ligands arrange around this combination of metal ions to match their electronic preferences. $\mathrm{H}_{2} \mathrm{~L} \cdot \mathrm{HBr}, \mathrm{Zn}\left(\mathrm{BF}_{4}\right)_{2}$ and $\mathrm{Ti}\left(\mathrm{O}^{i} \mathrm{Pr}\right)_{4}$ were<smiles>CC#CC(C)(C)C(C)(C)C</smiles>

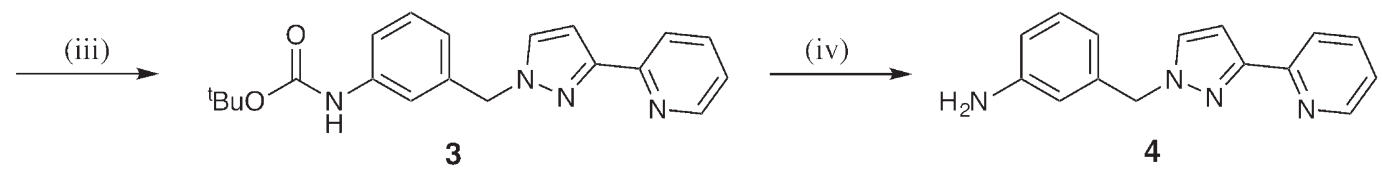<smiles>COc1cccc(NC(=O)c2c(OC)cccc2C(=O)Nc2cccc(Cn3ccc(-c4ccccn4)n3)c2)c1OC</smiles><smiles>Cc1cccc(Cn2ccc(-c3ccccn3)n2)c1</smiles>

Scheme 2 Synthesis of $\mathrm{H}_{2} \mathrm{~L}$, (i) $\mathrm{Boc}_{2} \mathrm{O}$, THF; (ii) $\mathrm{CBr}_{4}, \mathrm{PPh}_{3}, \mathrm{THF}$; (iii) 3-(2-pyridyl)-1H-pyrazole, $\mathrm{NaOH}_{\text {(aq), }}$ THF; (iv) trifluoroacetic acid, $\mathrm{CH}_{2} \mathrm{Cl}_{2} ;(\mathrm{V}) \mathrm{SOCl}_{2}, \mathrm{DMF}$ ( vi) 4, $\mathrm{CH}_{2} \mathrm{Cl}_{2}, \mathrm{Et}_{3} \mathrm{~N}$; (vii) $\mathrm{BBr}_{3}, \mathrm{CH}_{2} \mathrm{Cl}_{2}, \mathrm{H}_{2} \mathrm{O}$. 


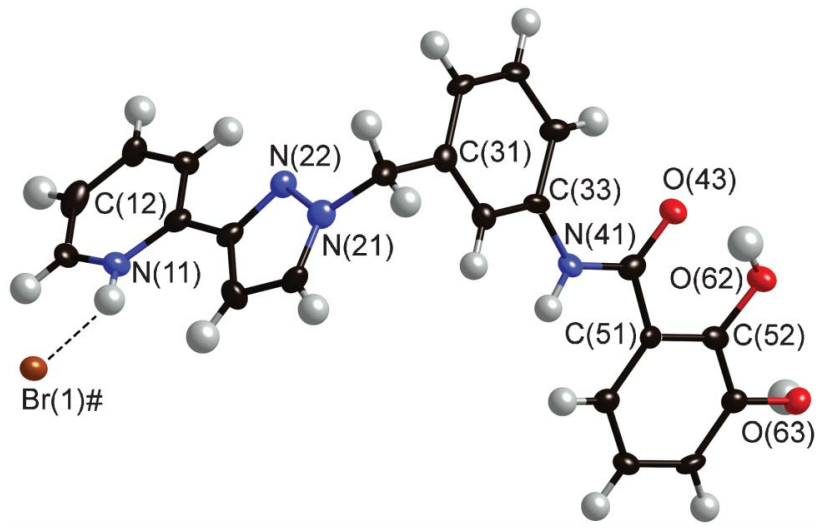

Fig. 1 Molecular structure of $\mathrm{H}_{2} \mathrm{~L} \cdot \mathrm{HBr}$. Non-H atoms are shown with $40 \%$ thermal ellipsoids, the hydrogen-bond between the protonated pyridine and the bromide anion is shown with a dotted line. Atoms labeled ' $\#$ ' are at equivalent position $(-x$, $1-y, z)$.

combined in a $3: 1: 1$ ratio in $\mathrm{MeOH}$ with a few drops of $\mathrm{Et}_{3} \mathrm{~N} . \S$ Stirring at room temperature quickly afforded an orange precipitate which was filtered off and washed with $\mathrm{MeOH}$ and ether. Crystallisation by diffusion of $\mathrm{MeOH}$ vapour into a dmf solution of the complex afforded X-ray quality orange plates; the resulting structure is shown in Fig. 3 and 4.

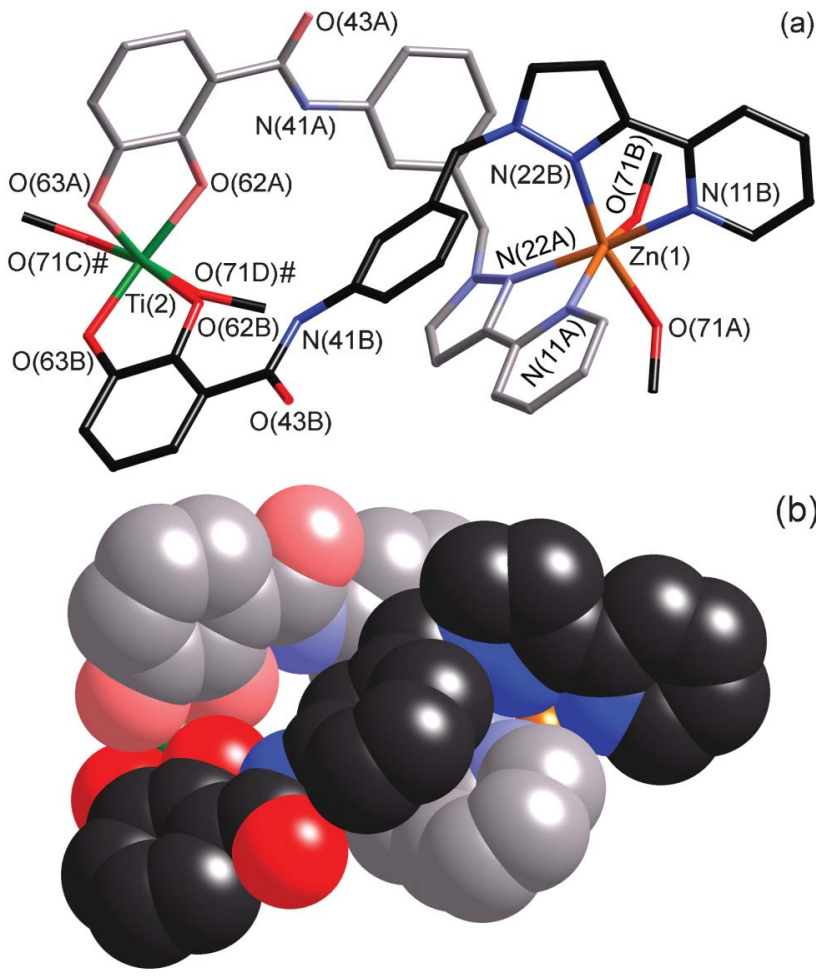

Fig. 2 Two views of one of the four dinuclear double helical subunits that form the edges of tetrameric assembly. (a) A wire-frame view showing the atomic numbering scheme; the methoxide ligands are shown (but not the adjacent atoms to which they bridge). Atoms labeled ' $\#$ ' are at equivalent position $(-x, y, 0.5-z)$. (b) A space-filling view from the same perspective, with one of the ligands shown in paler colours for clarity (methoxide ligands omitted).
The complex has the formulation $\left[\mathrm{Ti}_{4} \mathrm{Zn}_{4} \mathrm{~L}_{8}(\mu-\mathrm{OMe})_{8}\right]$ $\cdot 4 \mathrm{MeOH} \cdot 4 \mathrm{dmf}$ and has an unusual structure which is a square array of four heterodinuclear $\left\{\mathrm{TiZnL}_{2}\right\}^{2+}$ double helicates that are connected head-to-tail [i.e. $\mathrm{Zn}$ (II) terminus to Ti(Iv) terminus] by a pair of methoxide bridges. Each double helicate fragment - an edge of the square assembly - has the two bridging ligands oriented in the same direction, such that the $\mathrm{Zn}$ (II) ion is coordinated by two pzpy units at one end and the Ti(Iv) ion is coordinated by two $\mathrm{cat}^{2-}$ units at the other, i.e. the ligands are arranged so as to define 'hard' and 'soft' binding pockets. There are two crystallographically independent types of double helicate unit, one containing $\mathrm{Ti}(1) / \mathrm{Zn}(2)$ and the other containing $\mathrm{Ti}(2) /$

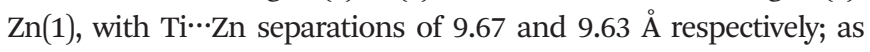
such the tetrameric $\{\mathrm{TiZn}\}_{4}$ array has crystallographically-imposed twofold symmetry. The Ti(2)/Zn(1) double helicate unit is shown in wire-frame and space-filling modes in Fig. 2. Weak interactions between ligands $\left(\pi-\pi\right.$ and $\left.\mathrm{CH}^{\cdots} \cdots \pi\right)$ within each double helicate subunit are evident; for example Fig. 2a illustrates a $\pi$-stacking interaction between a phenyl spacer of one ligand and a coordinated pyrazolyl-pyridine unit of the other.

All four dinuclear double helicates units have the same sense of twist within the assembly, i.e. the whole tetrameric assembly is homochiral. A pair of bridging methoxide ions connecting each helicate to the next in the cyclic tetramer means that each $\mathrm{Zn}$ (II) ion has an $\mathrm{N}_{4} \mathrm{O}_{2}$ donor set and each Ti(Iv) ion has an $\mathrm{O}_{6}$ donor set. The $\mathrm{Zn}(1) \cdots \operatorname{Ti}(1)$ and $\mathrm{Zn}(2){ }^{\cdots} \cdot \mathrm{Ti}(2)$ separations across the methoxide bridges in the $\mathrm{ZnTi}(\mu-\mathrm{OMe})_{2}$ units are 3.18 and $3.20 \AA$ respectively. Individual bond lengths and angles around the approximately octahedral metal ions are unremarkable. Fig. 3 shows the entire complex, with the two $\mathrm{Zn}(1) / \mathrm{Ti}(2)$ double helicates (approximately vertical in the figure) shown with blue and green bridging ligands, and the two $\mathrm{Zn}(2) / \mathrm{Ti}(1)$ double helicates (approximately horizontal in the figure) shown with purple and gold ligands. A space-filling view is in Fig. 4, and Fig. 5 shows just the octanuclear metal

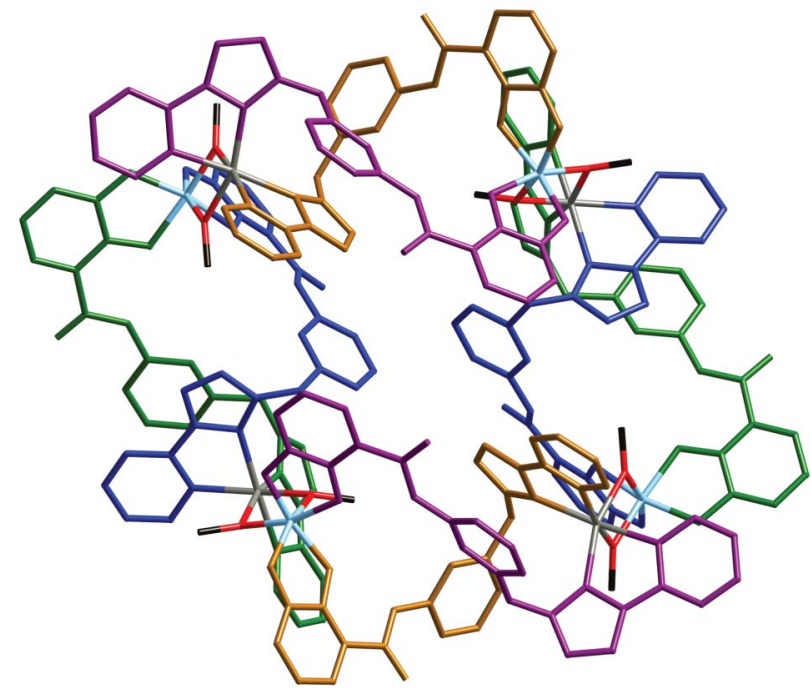

Fig. 3 A view of the complete tetrameric assembly. The dinuclear double helicate units are shown with the atoms of each ligand coloured green/blue or purple/gold; $\mathrm{Zn}=$ grey; $\mathrm{Ti}=$ cyan; $\mathrm{O}=$ red; $\mathrm{C}=$ black . 


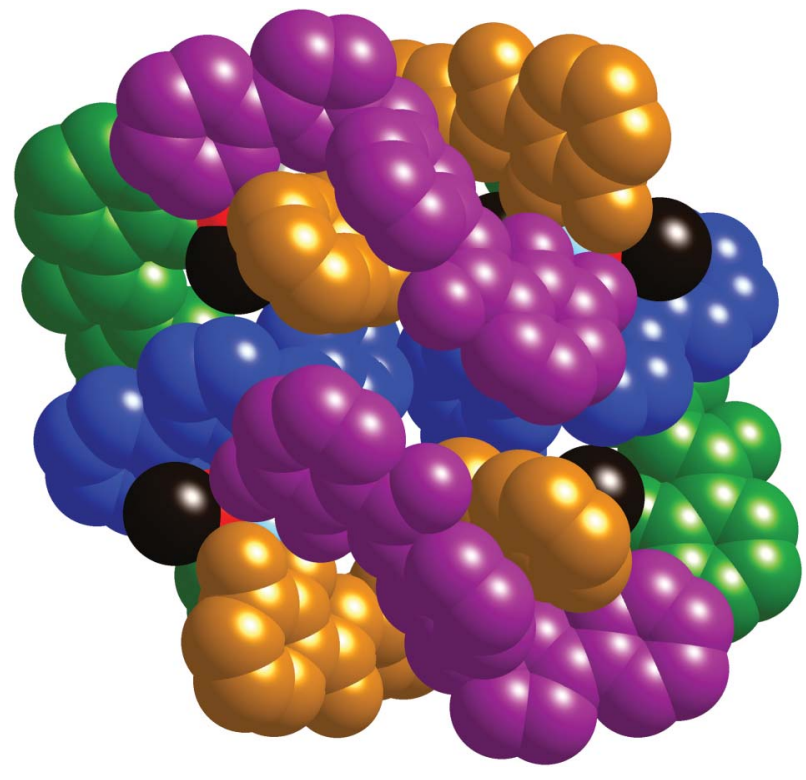

Fig. $4 \mathrm{~A}$ space-filling view of the whole complex $\left[\mathrm{Ti}_{4} \mathrm{Zn}_{4} \mathrm{~L}_{8}(\mu-\mathrm{OMe})_{8}\right]$ with the bridging ligands coloured as in Fig. 3 (the individual dinuclear double helicate components are green/blue or purple/gold).

skeleton and the methoxide bridges that hold the four double helicates together.

Once formed, the crystals are highly insoluble and can only be redissolved in a strongly competitive solvent like DMSO; ES mass spectra on the resultant solutions showed, unsurprisingly, only fragments with no evidence for the intact complex under those conditions.

Cyclic helicate structures in general are now well known ${ }^{16}$ but this example is unprecedented for two reasons. Firstly, a one-pot self-assembly reaction results in formation of a cyclic heteronuclear array in which $\mathrm{Zn}$ (II) and Ti(Iv) ions alternate around the circumference due to the presence of two quite different binding sites in the non-symmetrical ligand; this contrasts with the usual situation in cyclic helicates in which all metal ions are the same. Whilst we are not aware of any other heterometallic cyclic helicates, we note that Rice et al. recently reported a threecomponent cyclic helicate from a single reaction which contains $\mathrm{Cu}$ (II) ions and two types of bridging ligand. ${ }^{17}$ In addition, this cyclic structure is unusual in being formed from four distinct dinuclear double helicates connected by methoxide bridges, rather than the more usual type of structure in which ditopic or tritopic bridging ligands overlap in a continuous sequence around the periphery of the complex. ${ }^{16}$ Using the same methodology as employed for $\mathrm{H}_{2} \mathrm{~L}$ we can readily synthesise a wide range of heterotopic catecholate/pyrazolyl-pyridine bridging ligands as a basis for self-assembled heterometallic arrays.

We thank the EPSRC for financial support, and Dr Andrew Stephenson for assistance with the crystallography.

\section{References}

† Crystal data for $\mathrm{H}_{2} \mathrm{~L} \cdot \mathrm{HBr}\left(\mathrm{C}_{22} \mathrm{H}_{19} \mathrm{BrN}_{4} \mathrm{O}_{3}\right)$ : monoclinic, space group $P 2_{1} / c$, $M_{\mathrm{r}}=467.32, a=4.807(3), b=18.377(13), c=22.149(15) \AA, \beta=91.68(3)^{\circ}, V=$

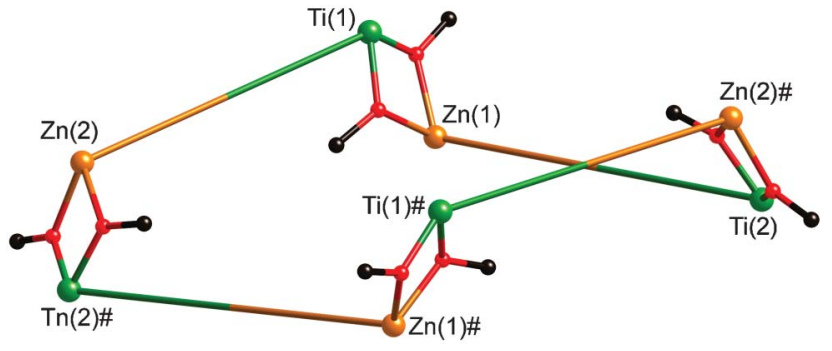

Fig. $5 \mathrm{~A}$ view of the complex $\left[\mathrm{Ti}_{4} \mathrm{Zn}_{4} \mathrm{~L}_{8}(\mu-\mathrm{OMe})_{8}\right]$ showing only the eight metal ions and the bridging methoxide ligands which connect each $\mathrm{Ti} / \mathrm{Zn}$ double helicate (a long 'edge' in this view) into a cyclic tetramer $(C=$ black, $\mathrm{O}=\mathrm{red})$. Atoms labeled '\#' are at equivalent position $(-x, y, 0.5-z)$.

$1956(2) \AA^{3}, Z=4, D_{\mathrm{c}}=1.587 \mathrm{~g} \mathrm{~cm}^{-3}, T=100(2) \mathrm{K}, \mu(\mathrm{Mo}-\mathrm{K} \alpha)=2.135 \mathrm{~mm}^{-1}$. Refinement of 271 parameters using 2780 independent reflections $\left(R_{\text {int }}=\right.$ $0.107)$ converged at $R_{1}$ [for data with $\left.I>2 \sigma(I)\right]=0.075, w R_{2}$ (all data) $=$ 0.214.Crystal data for $\left[\mathrm{Ti}_{4} \mathrm{Zn}_{4} \mathrm{~L}_{8}(\mu-\mathrm{OMe})_{8}\right] \cdot 4 \mathrm{MeOH} \cdot 4 \mathrm{dmf}$ : $\mathrm{C}_{200} \mathrm{H}_{196} \mathrm{~N}_{36} \mathrm{O}_{40} \mathrm{Ti}_{4} \mathrm{Zn}_{4}$ : monoclinic, space group $C 2 / c, M_{\mathrm{r}}=4197.01, a=$ 45.96(3), $b=14.997(8), c=34.57(2) \AA, \beta=119.729(8)^{\circ}, V=20692(21) \AA^{3}, Z=$ $4, D_{\mathrm{c}}=1.347 \mathrm{~g} \mathrm{~cm}^{-3}, T=100(2) \mathrm{K}, \mu(\mathrm{Mo}-\mathrm{K} \alpha)=0.683 \mathrm{~mm}^{-1}$. Refinement of 1041 parameters using 14644 independent reflections $\left(R_{\text {int }}=0.068\right)$ converged at $R_{1}$ [for data with $\left.I>2 \sigma(I)\right]=0.109, w R_{2}$ (all data) $=0.300$.

Data collections were performed by the EPSRC National Crystallography Service at the University of Southampton. ${ }^{18}$ Data were corrected for absorption using empirical methods (SADABS) $)^{19}$ based upon symmetryequivalent reflections combined with measurements at different azimuthal angles. The structures were solved and refined using the SHELX suite of programs. ${ }^{20}$ In the structure of $\left[\mathrm{Ti}_{4} \mathrm{Zn}_{4} \mathrm{~L}_{8}(\mu-\mathrm{OMe})_{8}\right] \cdot 4 \mathrm{MeOH} \cdot 4 \mathrm{dmf}$, in addition to the solvent molecules that could be located and refined, large void volumes contained diffuse electron density that could not satisfactorily be modeled arising from severely disordered solvent molecules. This electron density was removed from the refinement using the 'SQUEEZE' function in PLATON; ${ }^{21}$ details are in the CIF. The values for molecular formula, formula weight, density, $F(000)$ and so on given above do not include the contribution from these disordered solvents and are therefore necessarily approximations. These crystals diffracted weakly and required numerous restraints and constraints to achieve a stable refinement. In particular all ligand aromatic rings were constrained to be planar; restraints were applied to bond distances and thermal displacement parameters of adjacent atoms to keep them similar; and restraints were applied to bond distances of the solvent molecules to keep the geometries reasonable.

$\S$ Preparation of $\left[\mathrm{Ti}_{4} \mathrm{Zn}_{4} L_{8}(\mu-\mathrm{OMe})_{8}\right] \cdot 4 \mathrm{MeOH} \cdot 4 d m f$. A solution of $\mathrm{Ti}\left(\mathrm{O}^{i} \mathrm{Pr}\right)_{4}$ $(8.5 \mathrm{mg}, 0.03 \mathrm{mmol})$ in $\mathrm{MeOH}\left(5 \mathrm{~cm}^{3}\right)$ was added to a stirred solution of $\mathrm{H}_{2} \mathrm{~L}$ (39 mg, $\left.0.1 \mathrm{mmol}\right)$ in $\mathrm{MeOH}\left(3 \mathrm{~cm}^{3}\right)$ causing the solution to turn yellow. A solution of $\mathrm{Zn}\left(\mathrm{BF}_{4}\right)_{2} \cdot 6 \mathrm{H}_{2} \mathrm{O}(10.2 \mathrm{mg}, 0.03 \mathrm{mmol})$ in $\mathrm{MeOH}\left(2 \mathrm{~cm}^{3}\right)$ was then added. Excess $\mathrm{Et}_{3} \mathrm{~N}\left(1 \mathrm{~cm}^{3}\right)$ was added and the mixture was stirred in the dark at room temperature for $24 \mathrm{~h}$. A fine orange precipitate was collected and washed with $\mathrm{MeOH}$. X-Ray quality crystals were grown by slow diffusion of $\mathrm{MeOH}$ into a solution of the complex in DMF. Yield: 13 $\mathrm{mg}, 0.003 \mathrm{mmol}, 46 \%$. Found: C, 54.3; H, 3.9; N, 11.3\%. Calcd. For $\mathrm{C}_{184} \mathrm{H}_{152} \mathrm{~N}_{32} \mathrm{O}_{48} \mathrm{Ti}_{4} \mathrm{Zn}_{4}:$ C, 54.8; H, 3.8; N, $11.1 \%$.

1 (a) M. D. Ward and P. R. Raithby, Chem. Soc. Rev., 2013, 42, 1619; (b) R. Chakrabarty, P. S. Mukherjee and P. J. Stang, Chem. Rev., 2011, 111, 6810; (c) D. Philp and J. F. Stoddart, Angew. Chem., Int. Ed. Engl., 1996, 35, 1155.

2 Q.-F. Sun, J. Iwasa, D. Ogawa, Y. Ishido, S. Sato, T. Ozeki, Y. Sei, K. Yamaguchi and M. Fujita, Science, 2010, 328, 1144.

3 (a) A. Stephenson, S. P. Argent, T. Riis-Johannessen, I. S. Tidmarsh and M. D. Ward, J. Am. Chem. Soc., 2011, 133, 858; (b) A. Stephenson, D. Sykes and M. D. Ward, Dalton Trans., 2013, 42, 6756.

4 (a) T. K. Ronson, S. Zarra, S. P. Black and J. R. Nitschke, Chem. Commun., 2013, 49, 2476; (b) Z. Zhao, Y.-R. Zheng, M. Wang, J. 
B. Pollock and P. J. Stang, Inorg. Chem., 2010, 49, 8653; (c) K.C. Sham, S.-M. Yiu and H.-L. Kwong, Inorg. Chem., 2013, 52, 5648.

5 P. N. W. Baxter, J.-M. Lehn, G. Baum and D. Fenske, Chem.-Eur. J., 1999, 5, 102.

6 B. Icli, E. Sheepwash, T. Riis-Johannessen, K. Schenk, Y. Filinchuk, R. Scopelliti and K. Severin, Chem. Sci., 2011, 2, 1719.

7 A. K. Bar, G. Mostafa and P. S. Mukherjee, Inorg. Chem., 2010, 49, 7647.

8 (a) D. Imbert, M. Cantuel, J.-C. G. Bünzli, G. Bernardinelli and C. Piguet, J. Am. Chem. Soc., 2003, 125, 15698; (b) M. Albrecht, I. Latorre, G. Mehmeti, K. Hengst and I. Oppel, Dalton Trans., 2011, 40, 12067; (c) E. C. Constable and J. V. Walker, J. Chem. Soc., Chem. Commun., 1992, 884; (d) S. P. Argent, H. Adams, L. P. Harding, T. Riis-Johannessen, J. C. Jeffery and M. D. Ward, New J. Chem., 2005, 29, 904; (e) C. Piguet, G. Hopfgartner, B. Bocquet, O. Schaad and A. F. Williams, J. Am. Chem. Soc., 1994, 116, 9092.

9 S. Hiraoka, Y. Sakata and M. Shionoya, J. Am. Chem. Soc., 2008, 130, 10058.

10 H. B. Wu and Q. M. Wang, Angew. Chem., Int. Ed., 2009, 48, 7343.

11 X. K. Sun, D. W. Johnson, D. L. Caulder, K. N. Raymond and E. H. Wong, J. Am. Chem. Soc., 2001, 123, 2752.

12 M. D. Ward, Chem. Commun., 2009, 4487.

13 D. Fiedler, D. H. Leung, R. G. Bergman and K. N. Raymond, Acc. Chem. Res., 2005, 38, 349.

14 M. Albrecht, Y. Shang, T. Rhyssen, J. Stubenrauch, H. D. F. Winkler and C. A. Schalley, Eur. J. Org. Chem., 2012, 2422.
15 D. L. Caulder, C. Bruckner, R. E. Powers, S. Konig, T. N. Parac, J. A. Leary and K. N. Raymond, J. Am. Chem. Soc., 2001, 123, 8923.

16 (a) J.-F. Ayme, J. E. Beves, D. A. Leigh, R. T. McBurney, K. Rissanen and D. Schultz, J. Am. Chem. Soc., 2012, 134, 9488; (b) O. R. Clegg, R. V. Fennessy, L. P. Harding, C. R. Rice, T. RiisJohannessen and N. C. Fletcher, Dalton Trans., 2011, 40, 12381; (c) S. P. Argent, H. Adams, T. Riis-Johannessen, J. C. Jeffery, L. P. Harding, O. Mamula and M. D. Ward, Inorg. Chem., 2006, 45, 3905; (d) J. Hamblin, F. Tuna, S. Bunce, L. J. Childs, A. Jackson, W. Errington, N. W. Alcock, H. Nierengarten, A. V. Dorsselaer, E. Leize-Wagner and M. J. Hannon, Chem.-Eur. J., 2007, 13, 9286; (e) O. Mamula, A. von Zelewsky, P. Brodard, C. W. Schläpfer, G. Bernardinelli and H. Stoeckli-Evans, Chem.Eur. J., 2005, 11, 3049; (f) B. Hasenknopf, J.-M. Lehn, N. Boumediene, A. Dupont-Gervais, A. van Dorsselaer, B. Kneisel and D. Fenske, J. Am. Chem. Soc., 1997, 119, 10956; (g) C. S. Campos-Fernández, B. L. Schottel, H. T. Chifotides, J. K. Bera, J. Bacsa, J. M. Koomen, D. H. Russell and K. R. Dunbar, J. Am. Chem. Soc., 2005, 127, 12909.

17 K. E. Allen, R. A. Faulkner, L. P. Harding, C. R. Rice, T. RiisJohannessen, M. L. Voss and M. Whitehead, Angew. Chem., Int. Ed., 2010, 49, 6655.

18 S. J. Coles and P. A. Gale, Chem. Sci., 2012, 3, 683.

19 G. M. Sheldrick, SADABS: A program for absorption correction with the Siemens SMART system, University of Göttingen, Germany, 1996.

20 G. M. Sheldrick, Acta Crystallogr., Sect. A: Found. Crystallogr., 2008, 64, 112.

21 A. L. Spek, Acta Crystallogr., Sect. D: Biol. Crystallogr., 2009, 65, 148. 